\title{
Chrysanthemum Response to Timing of Paclobutrazol and Uniconazole \\ Sprays
}

\author{
David A. Gilbertz \\ Department of Horticulture, University of Georgia, Georgia Station, \\ Grifjin, GA 30223
}

Additional index words. Dendranthema $\times$ grandiflorum, growth regulators, daminozide, pinching

\begin{abstract}
Spray applications of 15 or $30 \mathrm{mg}$ uniconazole or 30 or $60 \mathrm{mg}$ paclobutrazol/ liter (20 ml/1.5-liter pot) were sprayed 0, 2, or 4 weeks after pinching of Dendranthema $\times$ grandiflorum (Ramat.) Kitamura 'Bright Golden Anne' plants. Plants were shorter the earlier growth regulators were applied. Plants were more responsive to uniconazole, requiring paclobutrazol at up to four times the uniconazole concentration to achieve the same height control. Time to flowering was also lengthened the earlier applications were made, up to 3 days compared to nontreated plants. Flower diameter was only minimally affected by the treatments. Chemical names used (2RS,3RS)-1-(4-chlorophenyl)-2-1,1-dimethylethyl)-(1H-1,2,4-triazol-1-yl)pentan-3-ol(-paclobutrazol);(E)-l(p-chlorophenyl) -4,4-dimethyl-2-( 1,2,4-triazol-1-yl-1-penten-3-ol) (uniconazole).
\end{abstract}

Paclobutrazol and uniconazole are effective inhibitors of chrysanthemum stem elongation (Barrett and Nell, 1990; Gilbertz and Pollard, 1988; Starman, 1990), but obtaining consistent results without excessive stunting or adversely affecting flowering has been a problem. Timing of paclobutrazol and uniconazole spray application was an important factor in growth control of petunia (Petunia hybrida Villm.) and marigold (Tagetes erects L.), in which earlier application generally resulted in less stem elongation (Gilbertz, 1988). Earlier spray applications can result in better compound contact with soil and presumably stems since there is less coverage by plant canopies. Application of paclobutrazol to soil and stems was shown to be more effective for height control than those made to leaves in chrysanthemum (Barrett and Bartuska, 1982). In the experiments reported here, the effect of spray timing on chrysanthemums using triazole compounds was determined.

Two experiments in a randomized complete-block design with three replications of three plants each were conducted Fall 1989 and Winter 1990. The results of the two studies were similar, and, therefore, only the data from Winter 1990 are presented. Four rooted cuttings of Dendranthema $\times$ grandiflorum (Ramat.) Kitamura 'Bright Golden Anne' were planted into 1.5-liter $(15 \mathrm{~cm})$ pots filled with a commercial peat-lite medium (Fisons Western Corp., Downers Grove,

\footnotetext{
Received for publication 4 Mar. 1991. Accepted for publication 9 Oct. 1991. Appreciation is extended to Yoder Bros., Barberton, Ohio, for donating chrysanthemums; to Valent Corp., Fresno, Calif, for financial support; and V.W. Pollard for his valuable technical assistance during these experiments. The cost of publishing this paper was defrayed in part by the payment of page charges. Under postal regulations, this paper therefore must be hereby marked advertisement solely to indicate this fact.
}

methylhydrazide) (daminozide) was excluded from contrasts for week of application, since it was applied for comparison only at 2 weeks after pinching. Total stem length and final height data responded similarly; therefore, only final height data are presented. Final height showed an interaction between triazole treatment and week of application, but other variables showed no interaction.

The triazoles produced plants similar in height to those treated with daminozide at $5000 \mathrm{mg} \cdot$ liter $^{-1}$ (Table 1); however, plant height was more responsive to uniconazole than paclobutrazol. Plants required paclobutrazol at up to four times the uniconazole concentration to achieve the same height control. Barrett and Nell (1990) found that stem elongation response was similar to sprays of paclobutrazol at $50 \mathrm{mg} \cdot \mathrm{liter}^{-1}$ and uniconazole at $27 \mathrm{mg} \cdot \mathrm{liter}^{-1}$ for 'Nob Hill' chrysanthemum but that differences between the compounds widened with increasing rates.

Height was more effectively controlled the earlier plants were treated with the triazoles. Paclobutrazol at 30 and $60 \mathrm{mg} \cdot$ liter $^{-1}$ reduced plant height $27 \%$ and $40 \%$, respectively, relative to that of controls when applied at pinching, but the same rates only caused $3 \%$ and $7 \%$ reductions, respectively, when applied at week 4. Adequate height control was still achieved with uniconazole at 30 $\mathrm{mg} \cdot$ liter $^{-1}$ when applied at week 4 , but the same concentration caused excessive reductions in height (53\% and 43\%) when applied at week 0 or 2 , respectively, compared to controls.

Several factors may account for the timing response on height control with the triazoles. Paclobutrazol has been shown to have limited effect on apical growth when applied to leaves, but the chemical applied to stems or soil is readily taken up, presumably via the xylem (Barrett and Bartuska, 1982). Similarly, movement of uniconazole is primarily acropetal (Sterrett, 1988). The earlier treatments in this study probably permitted more chemical contact with the soil and more complete stem coverage because plants had fewer leaves than plants in later treatments. Therefore, the greater surface area of larger plants allowed less chemical contact with active uptake sites. As a result, plant response was reduced.

The limited response with later treatments may also be due to the stem elongation that had already occurred when these treatments were applied ( $26 \%$ and $71 \%$ of total elongation at weeks 2 and 4, respectively) and, therefore, less retardation was possible.

To counteract these problems, later applications may require more solution than 20 $\mathrm{ml} /$ plant for adequate coverage, thereby increasing the a.i. per plant. Bailey (1989) found that simply increasing the spray carrier volume while maintaining the same uniconazole rate per pot would not alone cause less stem elongation.

Flowering was not delayed by the triazoles compared to nontreated or daminozide-treated plants. Plants treated at pinch were slower to flower than those treated later, particularly for uniconazole-treated plants, which flow- 
Table 1. Response of 'Bright Golden Anne' chrysanthemum to timing of spray applications using two triazole growth regulators: paclobutrazol and uniconazole.

\begin{tabular}{|c|c|c|c|c|c|c|c|c|c|}
\hline \multirow[b]{2}{*}{ Chemical } & \multirow{2}{*}{$\begin{array}{c}\text { Concn } \\
\left(\mathrm{mg} \cdot \text { liter }^{-1}\right)\end{array}$} & \multirow{2}{*}{$\begin{array}{c}\text { Week of } \\
\text { application }\end{array}$} & \multirow{2}{*}{$\begin{array}{c}\text { Final ht } \\
(\mathrm{cm})\end{array}$} & \multirow{2}{*}{$\begin{array}{c}\text { Days to } \\
\text { flowering }\end{array}$} & \multirow{2}{*}{$\begin{array}{l}\text { Flower } \\
\text { diam } \\
(\mathrm{cm})\end{array}$} & \multicolumn{4}{|c|}{ Dry wt (g) } \\
\hline & & & & & & Leaf & Stem & Flower & Shoot \\
\hline None & & & 30 & 58 & 11 & 1.2 & 1.8 & 4.4 & 7.3 \\
\hline Daminozide (DAM) & 5000 & 2 & 22 & 58 & 11 & 1.0 & 1.2 & 3.9 & 6.1 \\
\hline \multirow{6}{*}{ Paclobutrazol (PAC) } & 30 & 0 & 22 & 59 & 11 & 0.9 & 1.0 & 3.2 & 5.0 \\
\hline & 30 & 2 & 24 & 57 & 11 & 0.9 & 1.2 & 3.6 & 5.7 \\
\hline & 30 & 4 & 29 & 57 & 11 & 1.0 & 1.6 & 4.1 & 6.7 \\
\hline & 60 & 0 & 18 & 60 & 10 & 0.9 & 0.8 & 3.0 & 4.7 \\
\hline & 60 & 2 & 22 & 58 & 11 & 1.0 & 1.2 & 4.2 & 6.4 \\
\hline & 60 & 4 & 28 & 57 & 10 & 1.1 & 1.6 & 3.8 & 6.4 \\
\hline \multirow{6}{*}{ Uniconazole (UNI) } & 15 & 0 & 18 & 60 & 10 & 0.8 & 0.6 & 2.8 & 4.2 \\
\hline & 15 & 2 & 21 & 58 & 11 & 1.0 & 1.0 & 3.6 & 5.7 \\
\hline & 15 & 4 & 27 & 58 & 11 & 1.0 & 1.4 & 3.7 & 6.0 \\
\hline & 30 & 0 & 14 & 61 & 10 & 0.7 & 0.4 & 2.4 & 3.6 \\
\hline & 30 & 2 & 17 & 58 & 10 & 1.1 & 0.9 & 3.5 & 5.4 \\
\hline & 30 & 4 & 25 & 58 & 10 & 1.0 & 1.4 & 4.0 & 6.4 \\
\hline \multicolumn{10}{|l|}{ Significance } \\
\hline Error mean square & & & 2.49 & 1.15 & 0.26 & 0.03 & 0.03 & 0.22 & 0.52 \\
\hline Control vs. triazoles & & & $* * *$ & NS & $* * *$ & $* * *$ & $* * *$ & $* * *$ & $* * *$ \\
\hline DAM vs. triazoles & & & NS & NS & $* * *$ & NS & $*$ & $*$ & * \\
\hline PAC vs. UNI & & & $* * *$ & $* * *$ & $*$ & NS & $* * *$ & $* * *$ & $* * *$ \\
\hline PAC 30 vs. $60 \mathrm{mg} \cdot$ liter $^{-1}$ & & & **** & NS & NS & NS & * & NS & NS \\
\hline UNI 15 vs. $30 \mathrm{mg} \cdot$ liter $^{-1}$ & & & $* * *$ & NS & NS & NS & NS & NS & NS \\
\hline Week, linear & & & $* * *$ & **** & NS & $* * *$ & $* * *$ & $* * *$ & $* * *$ \\
\hline Week, quadratic & & & $* * *$ & $* * *$ & ** & ** & NS & $* * *$ & ** \\
\hline \multicolumn{10}{|l|}{ Triazoles $\times$ week } \\
\hline (from ANOVA table) & & & ** & NS & NS & NS & NS & NS & NS \\
\hline
\end{tabular}

${ }^{2}$ Following the date of pinching.

yFollowing short-day initiation.

***,****,NsSignificant at $P=0.001,0.01$, or 0.05 or not significant at $P=0.05$, respectively. Daminozide and none treatments were excluded from comparisons for week of application.

ered up to 3 days after nontreated plants. Flower diameter was reduced up to $9 \%$ by the triazoles. Uniconazole sprays also have reduced flower diameter in other chrysanthemum cultivars (Starman, 1990; Wilfret, 1988). Although statistically significant, this reduction did not appear objectionable in practical terms.

Total shoot dry weight was limited primarily by stem dry weight, which was concomitant with less stem length. Both vegetative and reproductive growth were reduced the earlier treatments were applied, resulting in less dry weight in the three measured components of shoot dry weight. Preliminary studies have shown that triazole drenches limited stem elongation in vegetative chrysanthemum for 5 weeks, suggesting that reproductive stages of flowering plants could be affected by early application of the compounds (unpublished).
These experiments indicate that timing of application is important to height control achieved with uniconazole or paclobutrazol. Greatest response occurred with application on the date of pinch, but flowering was adversely affected. Later treatments had less effect on flowering. Plants were more sensitive to triazoles when applied on the date of pinching, suggesting fewer problems with overdosing when applied later in the crop cycle. Adequate height control was observed with uniconazole at $30 \mathrm{mg} \cdot$ liter ${ }^{-1}$ applied as late as 4 weeks after pinch, with minor adverse effects on flowering.

\section{Literature Cited}

Bailey, D.A. 1989. Uniconazole efficacy on chrysanthemum and poinsettia is not affected by spray carrier volume. HortScience 24:964-966.

Barrett, J.E. and C.A. Bartuska. 1982. PP333 effects on stem elongation dependent on site of application. HortScience 17:737-738.

Barrett, J.E. and T.A. Nell. 1990. Factors affecting efficacy of paclobutrazol and uniconazole on petunia and chrysanthemum. Acts Hort. 272:229-234.

Gilbertz, D.A. 1988. Response of marigold and petunia to timing of paclobutrazol and XE-1019 foliar spray application. HortScience 23:751. (Abstr.)

Gilbertz, D.A. and V.W. Pollard. 1988. Chrysanthemum response to methods of Sumagic application. Proc. Southern Nurseryman's Assn. Res. Conf. 33:231-233.

Starman, T.W. 1990. whole-plant response of chrysanthemum to uniconazole foliar sprays or medium drenches. HortScience 25:935-937.

Sterrett, J.P. 1988. XE-1019: Plant response, translocation and metabolism. J. Plant Growth Regulat. 7:19-26.

Wilfert, G.J. 1988. Effect of XE-1019 on height of containerized chrysanthemums. HortScience 23:819. (Abstr.) 